
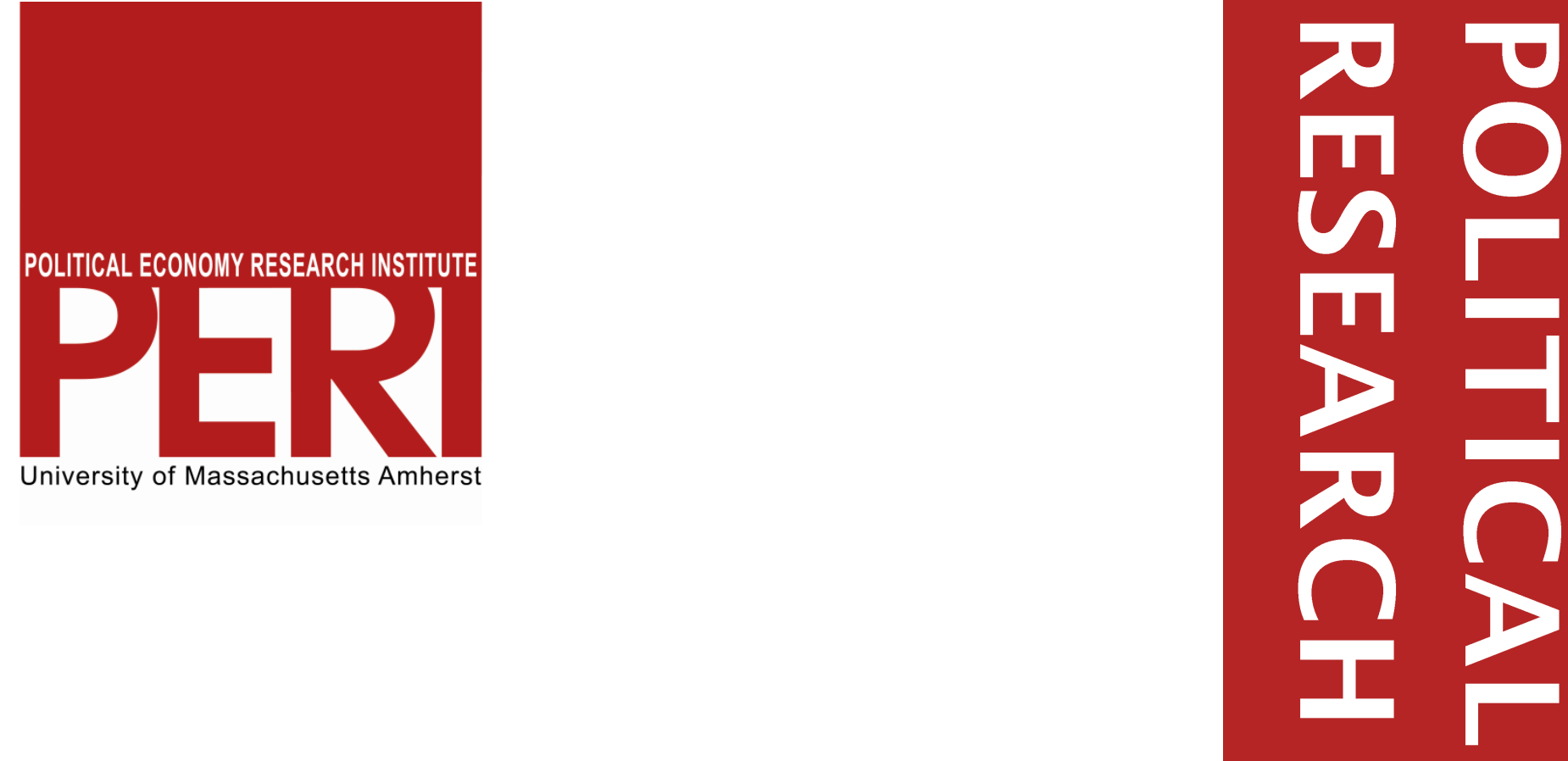

Is Inflation Targeting Operative in an Open Economy Setting?

Esteban Pérez Caldentey and Matías Vernengo

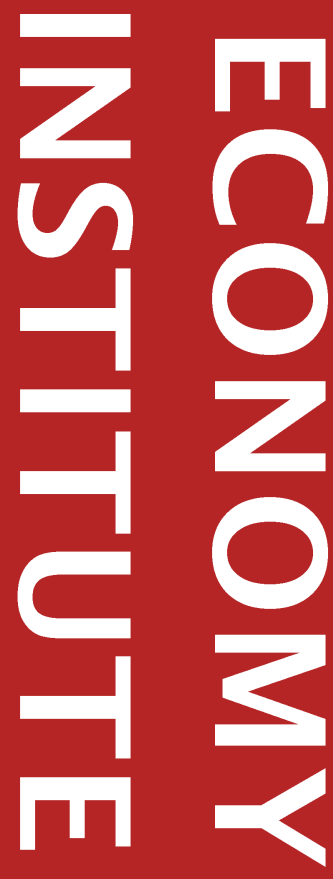

Gordon Hall

418 North Pleasant Street

Amherst, MA 01002

May 2013

Phone: 413.545 .6355

Fax: 413.577 .0261

peri@econs.umass.edu www.peri.umass.edu 


\title{
Is inflation targeting operative in an open economy setting?
}

\author{
Esteban Pérez Caldentey and Matías Vernengo ${ }^{1}$
}

\begin{abstract}
The justification for inflation targeting rests on three core propositions. The first is called 'lean against the wind', which refers to fact that the monetary authority contracts (expands) aggregate demand below capacity when the actual rate of inflation is above (below) target. The second is 'the divine coincidence', which means that stabilizing the rate of inflation around its target is tantamount to stabilizing output around its full employment level. The third proposition is that of stability. This means that the inflation target is part of an equilibrium configuration which generates convergence following any small disturbance to its initial conditions. These propositions are derived from a closed economy setting which is not representative of the countries that actually have adopted inflation targeting frameworks. Currently there are 27 countries, 9 of which are classified as industrialized and 18 as developing countries that have explicitly implemented a fully fledged inflation targeting regime (FFIT). These countries are open economies and are concerned by the evolution of the external sector and the exchange rate as proven by their interventions in the foreign exchange markets. We show that these three core propositions and the practice of inflation targeting are inoperative in an open economy context.
\end{abstract}

Key Words: Inflation Targeting, Open Economies, Exchange Rate

JEL Codes: E42, E58, F41

\footnotetext{
${ }^{1}$ Economic Commission for Latin America and the Caribbean (ECLAC); Central Bank of Argentina and University of Utah. The opinions here expressed are those of the authors and may not coincide with those of the institutions with whom they are affiliated.
} 


\section{Introduction}

A full-fledged inflation targeting regime (FFIT) is generally defined as a framework consisting in the public announcement of numerical targets for the inflation rate with the explicit acknowledgement that a low and stable rate of inflation is the main objective of monetary policy. The framework also requires a commitment to transparency and accountability in the monetary policy decision making process and in its results.

Inflation targeting gained prominence as a monetary strategy since the late 1990s. Currently 27 countries, 9 of which are classified as industrialized and 18 as developing countries have explicitly implemented a fully fledged inflation targeting regime (FFIT). Inflation targeting is presented by its proponents as a coherent and flexible approach to monetary policy differing from the more rigid ones based on monetary rules or fixed exchange rates and proving to be a better and more successful alternative in the control of inflation.

In this paper we argue that the raison d'être and ultimately, the validity of a fully fledged inflation targeting regime is founded on three core propositions. The first states that the central bank follows a 'lean-against the wind' strategy in the implementation of monetary policy. This refers to the fact that provided the output gap is the policy variables, the monetary authority contracts aggregate demand below capacity when the actual rate of inflation is above target. ${ }^{2}$ The second one is an equivalency proposition termed 'the Divine Coincidence.' 3

This means that stabilizing the rate of inflation around its target is tantamount to stabilizing output around its full employment level. The main implication is that the monetary authorities should worry about inflation. The third proposition which follows from the previous two is that of stability. The inflation target is part of an equilibrium configuration of an economy derived from a Taylor rule, a New Keynesian Phillips curve and a standard aggregate demand function. Moreover, the economy will converge towards its equilibrium position following any small disturbance to its initial conditions. ${ }^{4}$

We also show that these three core propositions follow from a closed economy model that is hardly representative of the countries that have adopted inflation targeting and which are, by most criteria, open economies. Their concern for external conditions is illustrated by their active intervention in the foreign exchange markets. In line with the evidence presented, once the inflation targeting framework is modified to include the open economy dimension in a meaningful sense, we show that these three core propositions are inoperative theoretically and empirically and that the practice of inflation targeting leads to fundamental policy dilemmas. This presumes the utilization of the conventional model, often referred to as the New Consensus, which has several and significant flaws (e.g. Arestis, 2009).

The paper is divided into six sections. The first sketches the basics of inflation targeting with a focus on fully fledged inflation targeting (FFIT). The second section derives formally the

\footnotetext{
${ }^{2}$ See, Clarida Galí, and Gertler (1999).

${ }^{3}$ See, Blanchard and Gali (2005).

${ }^{4}$ See Setterfield (2006); Rochon and Setterfield (2007). Note that if the notion of a natural rate, which has significant logical problems, and not much evidence to favor it is abandoned, then the main conclusions about leaning against the wind and the Divine Coincidence do not hold.
} 
core propositions of inflation targeting using a quadratic loss function subject to the structure of the economy encapsulated in a New Keynesian Phillips curve and a IS function. The third section underscores the importance of the external sector for the economies that have adopted FFIT and shows empirically that these countries actively intervene in the foreign exchange market. The fourth section introduces the external sector in the inflation targeting framework and shows the inoperative character of the core propositions. The fifth section illustrates this point empirically for all 27 economies in the sample. The last section concludes.

\section{A basic sketch of inflation targeting}

Inflation targeting is traditionally defined as a monetary policy strategy framework consisting in the public announcement of numerical targets for the inflation rate, acknowledging that price stability is the fundamental goal of monetary policy and a firm commitment to transparency and accountability. ${ }^{5}$ Within the context of this definition, numerical targets can refer to a point inflation rate, a range or a point with a tolerance range. The inflation rate can refer to the consumer price index (CPI) as is the standard case for most developing economies or to the core CPI. ${ }^{6}$

Transparency means that the monetary authorities must communicate their targets, forecasts of inflation, decisions on monetary policy and the motivation for their decisions. Finally, accountability here means that the monetary authorities are responsible for attaining the announced objectives and subject to "public scrutiny for changes in their policy or deviations from their targets.",7

\footnotetext{
${ }^{5}$ Bernanke et al (1999, p.4) define inflation targeting as a: "framework for monetary policy characterized by the public announcement of official quantitative targets (or target ranges) for the inflation rate over one or more time horizons, and by the explicit acknowledgement that low, stable inflation is monetary policy's primary goal." According to Mishkin (2004) inflation targeting comprises five distinct but interrelated aspects: "(i) the public announcement of medium-term numerical targets for inflation; (ii) an institutional commitment to price stability as the primary goal of monetary policy; (iii) an information inclusive strategy in which many variables, and not just monetary aggregates or the exchange rate, are used for deciding the setting of policy instruments; iv) increased transparency of the monetary policy strategy through communication with the public and the markets about the plans, objectives, and decisions of the monetary policy authorities; and v) increased accountability of the central bank for attaining its inflation objectives.” Svensson (2007) provides a similar definition.

${ }^{6}$ Note that price stability is not an easy concept to define. It is defined generally in terms of the demand for money, i.e., a situation where agents do not change their demand for money in response to price changes. Angeriz and Arestis (2007) quote Greenspan (1988) on price stability: "a situation in which households and businesses in making their savings and investment decisions can safely ignore the possibility of sustained generalized price increases or price decreases." Clarida et al. (1999, p.1669) refer to price stability as the inflation rate at which inflation is no longer a public concern. According to these authors, an inflation rate between one and three percent meets this definition and perhaps the reason that explains the 3\% mean inflation target in the case of Chile.

${ }^{7}$ Svensson (2007, pp2-3) states: "In several countries inflation-targeting central banks are subject to more explicit accountability. In New Zealand, the Governor of the Reserve Bank of New Zealand is subject to a Policy Target Agreement, an explicit agreement between the Governor and the government on the Governor's Responsibilities. In the UK, the Chancellor of the Exchequer's remit to the Bank of England instructs the Bank to write a public letter explaining any deviation from the target larger than one percentage point and what actions the Bank is taking in response to the deviation. In several countries, central-bank officials are subject to public hearings.....and in several countries monetary policy is... subject to extensive reviews by independent experts."
} 
Table 1: FFIT countries, industrialized/developing, date of IT adoption, inflation target in 2012 and target horizon

\begin{tabular}{|c|c|c|c|c|c|}
\hline Country & $\begin{array}{l}\text { Industrialized/ } \\
\text { Developing }\end{array}$ & $\begin{array}{l}\text { Adoption } \\
\text { of inflation } \\
\text { targeting }\end{array}$ & $\begin{array}{l}\text { Target } \\
\text { measure }\end{array}$ & Target 2012 & Target horizon \\
\hline Armenia & $\mathrm{D}$ & 2006 & HCPI & $4 \%+/-1.5 \mathrm{pp}$ & Medium term \\
\hline Australia & $\mathrm{I}$ & 1993 & HCPI & $2 \%-3 \%$ & Medium term \\
\hline Brazil & $\mathrm{D}$ & 1999 & HCPI & $4.5 \%+/-2 \mathrm{pp}$ & Yearly target \\
\hline Canada & I & 1989 & $\mathrm{HCPI}$ & $2 \%$ & $\begin{array}{l}\text { Six-eight quarters; } \\
\text { current target extends } \\
\text { to December } 2016\end{array}$ \\
\hline Chile & $\mathrm{D}$ & 1999 & HCPI & $3 \%+/-1 \mathrm{pp}$ & Two years \\
\hline Colombia & $\mathrm{D}$ & 1999 & HCPI & $2 \%-4 \%$ & Medium term \\
\hline Czech Republic & $\mathrm{D}$ & 1997 & HCPI & $2 \%+/-1 \mathrm{pp}$ & $\begin{array}{l}\text { Medium term, 12-18 } \\
\text { months }\end{array}$ \\
\hline Ghana & $\mathrm{D}$ & $\begin{array}{l}(2002) \\
2007 \\
\end{array}$ & HCPI & $8.7 \%+/-2 \mathrm{pp}$ & 18-24 months \\
\hline Guatemala & $\mathrm{D}$ & 2005 & HCPI & $4.5 \%+/-1 \mathrm{pp}$ & End of year \\
\hline Hungary & $\mathrm{D}$ & 2001 & HCPI & $3 \%$ & Medium term \\
\hline Iceland & I & 2001 & HCPI & $2.50 \%$ & On average \\
\hline Indonesia & $\mathrm{D}$ & 2005 & HCPI & $4.5 \%+/-1 p p$ & Medium term \\
\hline Israel & $\mathrm{I}$ & $\begin{array}{c}(1992) \\
1997 \\
\end{array}$ & $\mathrm{HCPI}$ & $1 \%-3 \%$ & Within two years \\
\hline Mexico & $\mathrm{D}$ & 2001 & HCPI & $3 \%+/-1 \%$ & Medium term \\
\hline New Zealand & I & 1989 & HCPI & $1 \%-3 \%$ & Medium term \\
\hline Norway & I & 2001 & HCPI & $2.50 \%$ & Medium term \\
\hline Peru & $\mathrm{D}$ & 2002 & $\mathrm{HCPI}$ & $2 \%+/-1 p p$ & Continually \\
\hline Philippines & $\mathrm{D}$ & 2002 & $\mathrm{HCPI}$ & $4.0 \%+/-1 \mathrm{pp}$ & Medium term \\
\hline Poland & $\mathrm{D}$ & 1998 & HCPI & $2.5 \%+/-1 \mathrm{pp}$ & Medium term \\
\hline Romania & $\mathrm{D}$ & 2005 & HCPI & $3 \%+/-1 \mathrm{pp}$ & Medium term \\
\hline Serbia & $\mathrm{D}$ & $\begin{array}{c}(2006) \\
2009\end{array}$ & HCPI & $4.0 \%+/-1.5 \mathrm{pp}$ & Medium term \\
\hline South Africa & $\mathrm{D}$ & 2000 & HCPI & $3 \%-6 \%$ & Continually \\
\hline Korea, Rep. & $\mathrm{I}$ & 1998 & HCPI & $3 \%+/-1 \mathrm{pp}$ & Three years \\
\hline Sweden & I & 1995 & HCPI & $2 \%$ & Two years \\
\hline Thailand & $\mathrm{D}$ & 2000 & HCPI & $3.0 \%+/-1.5 \mathrm{pp}$ & Eight quarters \\
\hline Turkey & $\mathrm{D}$ & 2006 & HCPI & $5.0 \%+/-2 \mathrm{pp}$ & Three years \\
\hline $\begin{array}{l}\text { United } \\
\text { Kingdom }\end{array}$ & I & 1992 & HCPI & $2 \%$ & Continually \\
\hline
\end{tabular}

Source: Hammond (2012). Note: The parenthesis for some countries in column 3, indicate the year in which FFIT was adopted informally. The years without parenthesis refer to the year in which FFIT was adopted formally. We use the latter year as the reference point for our analysis and empirical results. 
The above definition typifies the components of a fully fledged inflation targeting regime (FFIT). There are currently 27 countries that have announced to be operating on a FFIT. Among these 18 (or $67 \%$ of the total) are developing and 9 (or $33 \%$ of the total) are developed countries. The greater majority of developed countries adopted inflation targeting in the 1990's. For their part developing countries implemented inflation targeting regimes mainly in the past decade (see Table 1).

In practice FFTI's do not, as a rule, follow 'a firm commitment to transparency and accountability.' The evidence indicates that a small majority ( $66.7 \%$ of total FFTI's) abide by the transparency criterion in so far as the respective central banks publish the minutes of the monetary authorities. Still this means that $33.3 \%$ do not. In terms of accountability, only in $25.9 \%$ of the country cases, do the Central Banks provide an open letter explaining their policy outcomes. However, the great majority $(70.4 \%$ of the total) have parliamentary hearings on monetary policy (See, Table 2 below).

Table 2: Percent of total FFIT countries, developed and industrialized that comply with different aspects of inflation targeting institutionality

\begin{tabular}{|c|c|c|c|c|}
\hline & $\begin{array}{c}\text { Percentage of } \\
\text { total }\end{array}$ & $\begin{array}{c}\text { Percentage of } \\
\text { developed } \\
\text { countries }\end{array}$ & $\begin{array}{c}\text { Percentage of } \\
\text { developing } \\
\text { countries }\end{array}$ & $\begin{array}{c}\text { Percentage of LA } \\
\text { countries }\end{array}$ \\
\hline \multicolumn{5}{|l|}{ Setting of the inflation target } \\
\hline Government & 11.1 & 22.2 & 5.6 & 0.0 \\
\hline Central Bank & 33.3 & 11.1 & 44.4 & 83.3 \\
\hline Both & 55.6 & 66.7 & 50.0 & 16.7 \\
\hline \multicolumn{5}{|l|}{ Decision making process } \\
\hline Consensus & 29.6 & 44.4 & 22.2 & 0.0 \\
\hline Governor & 3.7 & 11.1 & 0.0 & 0.0 \\
\hline Majority vote & 66.7 & 44.4 & 77.8 & 100.0 \\
\hline \multicolumn{5}{|l|}{ Acountability } \\
\hline Open letter (Afirmative) & 25.9 & 22.2 & 27.8 & 16.7 \\
\hline Open letter (Negative) & 74.1 & 77.8 & 72.2 & 83.3 \\
\hline Parliamentary hearing (Afirmative) & 70.4 & 100.0 & 55.6 & 100.0 \\
\hline Parliamentary hearing (Negative) & 29.6 & 0.0 & 44.4 & 0.0 \\
\hline \multicolumn{5}{|l|}{ Transparency } \\
\hline CB minutes published (Afirmative) & 66.7 & 66.7 & 66.7 & 83.3 \\
\hline CB minutes published (Negative) & 33.3 & 33.3 & 33.3 & 16.7 \\
\hline
\end{tabular}

Source: On the basis of Hammond (2012)

All countries, with no exceptions, have a time horizon to achieve their target inflation, illustrating the fact that these practice 'flexible inflation targeting' as opposed to 'strict inflation 
targeting.' Flexible inflation targeting implies that the monetary authorities or the central bank do not have only a monetary objective (stabilizing inflation) but also has a real objective (stabilizing real output). As put by Svensson (2007, p.1): "In practice inflation targeting is never 'strict' inflation targeting but always 'flexible' inflation targeting, in the sense that all inflation-targeting central banks...not only aim at stabilizing inflation around the inflation target but also put some weight on stabilizing the real economy....implicitly or explicitly stabilizing a measure of resource utilization such as the output gap between actual output and 'potential output'." The literature also refers to 'flexible' inflation targeting as pursuing stability of interest rates or of the variation of the exchange rate in an open economy. ${ }^{8}$

The adoption of 'flexible' inflation targeting entails pursuing a 'gradualist' approach to the achievement of monetary policy objectives. 'Flexible' inflation targeting and hence a gradualist approach to monetary policy is conceptually justified mainly on the grounds of uncertainty regarding: (i) the workings and current state of the economy; (ii) the transmission mechanisms and policy parameters; and (iii) the nature of external shocks as well. A gradualist policy can also contribute to buffer the effects on real variables caused by external shocks.

\section{Inflation targeting and its core propositions}

At a conceptual level the inflation targeting framework is generally presented and analyzed for a closed economy setting. More importantly, this closed economy context allows the derivation of the core propositions on which inflation targeting rests, including the lean against the wind feature, the occurrence of the 'divine coincidence' (i.e., that 'stabilizing inflation is equivalent to stabilizing output around its natural level', Blanchard, 2006, p. 413) and the stability properties, that make it such a desirable monetary policy from the point of view of the mainstream.

These three fundamental properties can be derived from 'first principles,' by assuming that inflation targeting is an optimal targeting rule derived from an explicit objective function. More precisely, central banks solve a "standard optimal control problem, choosing the path of the price level that minimizes a quadratic loss function subject to the constraints imposed by the linear structure of the economy" (Cecchetti and Kim, 2005, p.176). Formally the loss function is specified as,

$$
\text { (1) } L=\left(y_{a}-y_{n}\right)^{2}+\beta\left(\pi_{t}-\pi^{T}\right)^{2}+\gamma\left(i_{t}-i_{t-1}\right)^{2}
$$

Where $y_{a}, \quad y_{p}=$ actual and potential output; $\pi_{t}, \pi^{T}=$ actual and target inflation rates, and $i_{t}, i_{t}^{T}$ are the actual and target short-term nominal interest rates (i.e., the monetary policy rates). ${ }^{9}$

\footnotetext{
${ }^{8}$ See, Svensson $(1997,2007)$ and Jonas and Mishkin (2006).

${ }^{9}$ The loss function includes an interest rate smoothing term $\gamma\left(i_{t}-i_{t-1}\right)^{\mathbf{2}}$ that captures the empirical fact that central banks adjust interest rates according to a smooth path capturing the fact that the policy rate moves in sequences of small steps and that, interest rate reversals are 'infrequent.' See Sack \& Wieland (1999) and Amatto \& Laubach (2003). The quadratic nature of the loss function implies that a symmetry in the weight placed on the deviations above and below targets for both inflation and output. As a result, the specification of the loss function
} 
According to the logic imbedded in Eq. (1), a deviation of the rate inflation from its target or of output from its natural level produces a loss of utility for the Central Bank. The parameter $\beta$ and its particular value characterizes the degree to which a Central Bank is inflation averse. If $\beta=1$, (>1) the Central Bank places the same (greater) weight on output fluctuations as on the deviation of inflation from its target. The greater is the parameter $\beta$ the greater is the aversion towards inflation. To the extent to which, the control of inflation (which in this case means the reduction of the variance of the actual rate of inflation relative to its target point or range) is the hierarchical objective of the Central Bank (Svensson, 2004), $\beta$ is $>1$ by definition.

The loss function (Eq.1) is minimized subject to the 'structure of the economy,' captured by a New Keynesian Phillips curve $\left(\pi_{t}=E_{t} \pi_{t+\mathbf{1}}+\alpha\left(y_{a}-y_{n}\right)\right)$ and a standard aggregate demand curve $\left(y_{t}^{g}=-\varphi\left(i_{t}-E \pi_{t+1}\right)+E y_{t+1}^{g}\right)$, where $y_{t}^{g}$ is the output gap. This is stated formally as follows:

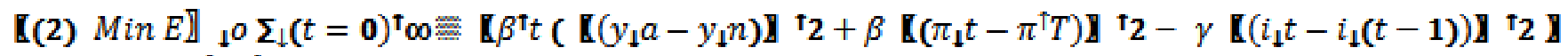
); where $\beta \in(1,0)$ is the discount factor.

s.t.
(3) $\pi_{t}=E_{t} \pi_{t+1}+\alpha\left(y_{a}-y_{n}\right)$
(4) $y_{t}^{g}=-\varphi\left(i_{t}-E \pi_{t+1}\right)+E y_{t+1}^{g}$
(Phillips Curve)
(IS Curve)

The first order conditions from the single period minimization of the objective function subject to both constraints are:

$$
\begin{aligned}
& \frac{\delta L}{\delta \pi_{t}}=\beta \pi_{t}^{g}-\lambda_{\mathbf{1}}=\mathbf{0} \\
& \frac{\delta L}{\delta y_{t}^{g}}=y_{t}^{g}+\alpha \lambda_{\mathbf{1}}-\lambda_{\mathbf{2}}=\mathbf{0} \\
& \frac{\delta L}{\delta i_{t}}=\gamma\left(i_{t}-i_{t-1}\right)-\lambda_{\mathbf{2}} \theta=\mathbf{0}
\end{aligned}
$$

suggest that since the central banks is concerned to the same extent by inflation and deflation, its reaction to both situations is also symmetric. 
Where $\lambda_{1}, \lambda_{\mathbf{2}}$ are the Langrangean multipliers and $\pi_{t}^{g}$ is the inflation gap. ${ }^{10}$

Using the first order condition and replacing it in the second order conditions and setting the second Lagrangean multiplier $\lambda_{\mathbf{2}}=\mathbf{0}$ yields the first important attribute of inflation targeting regimes, namely the 'lean against the wind' or countercyclical feature:

\section{(6) $y_{t}^{g}=-\alpha \beta \pi_{t}^{g} \quad($ Lean against the wind $)$}

Eq. (6) states that the minimization of the loss function and the optimal derivation of $y$ for each value of the inflation rate is, in fact, equivalent to a negative relation between the output and the inflation gap $\left(y_{t}^{g}, \pi_{t}^{g}\right.$ respectively). This implies that when the actual rate of inflation is above its target $\left(\pi_{t}>\pi^{T}\right.$ ), actual output is below its natural level $\left(y_{a}<y_{n}\right)$. In other words, within the inflation targeting logic, a rate of inflation above its target implies that the monetary authorities must contract aggregate demand by raising interest rates. In a similar manner, a rate of inflation below its target implies that the monetary authorities must expand aggregate demand by decreasing interest rates. Monetary policy is by design counter-cyclical (Clarida et al., 1999). The extent to which monetary policy is countercyclical depends on the parameters $\alpha$ and $\beta$.

A second important result derived from the above analysis is the absence of a trade-off between the output and inflation gap, the so-called 'divine coincidence' (Blanchard and Gali, 2005). More precisely, the specification of the loss function implies that the both the stabilization of inflation and output are desirable goals and that there is no conflict between both. As inflation approaches its target, output approaches its natural level as well. In line with Eq. (6), we imply it to mean that for any given values of $\alpha$ and $\beta$ the smaller is the inflation gap, the smaller will be the output gap.

\section{$(7)\left(y_{a}-y_{n}\right)=-\alpha \beta\left(\pi_{t}-\pi^{T}\right)$ and $\pi_{t} \rightarrow \pi^{T} \Rightarrow y_{a} \rightarrow y_{n}$ (Divine Coincidence) ${ }^{11}$}

\footnotetext{
${ }^{10}$ In the derivation of the first order conditions we do not address the issue of commitment/discretion which has been of recent relevance to the inflation targeting literature. When the monetary authorities do not have a commitment regarding the future path of inflation they practice discretion and the above optimization problem is reduced to a period-by-period optimization. Within the logic of inflation targeting when the central bank makes promises about future inflation (and thus acts under commitment), this has a positive effect on current inflation, since according to the literature, and also Eq. (3) above current inflation depends in part on future inflation. See Lam (2010).

${ }^{11}$ At first sight the lean against the wind and divine coincidence appear contradictory. According to the former there is a trade-off between stabilizing output and inflation. The latter denies the existence of a trade-off. A way to make both views compatible is to argue that the lean against the wind applies to the short-run while the divine coincidence is applicable to the long-run. This view finds its justification in Blanchard and Gali (2005) who argue that the divine coincidence applies in the absence of 'trivial rigidities.' This line of thinking implies that a positive inflation gap will result in actions tending the decrease the output below trend but that eventually output will converge towards its potential level. This is consistent with the stability proposition. Our empirical results on both properties apply to both long and short periods of time. Some countries have had FFIT in operation for roughly two decades while for others its application has not surpassed a period of ten years. In any case, according to our interpretation, we view
} 
The obvious implication is that since inflation stabilization is the hierarchical and main objective of monetary policy, it is equivalent to stabilizing output. As put by Blanchard (2006, p. 3):

"Stabilizing inflation also stabilizes the distance of output from first best - the welfarerelevant output gap. This is really an important result. It implies that central banks should indeed focus just on inflation, and we can sleep well at night. If they succeed in stabilizing inflation, they will automatically generate the optimal level of activity. Put another way, even if you do not care about inflation, but only about activity, you would still want the central bank to focus on inflation. Inflation targeting is an-output friendly rule." 12

Finally, the third important attribute of inflation targeting is the property of stability or more precisely that the inflation target is "part of an aggregate equilibrium configuration toward which the economy will return following any disturbance" (Setterfield, 2006, p. 657). In order to derive the stability attribute, the equation describing the reaction function of the central bank is required.

The reaction function can be obtained by manipulating the three first order conditions from the Central Bank optimization problem. That is, from the first and third first order conditions we obtain:

(10)

$\frac{\delta L}{\delta \pi_{t}}=\beta \pi_{t}^{g}-\lambda_{1}=0 \Leftrightarrow \lambda_{1}=\beta \pi_{t}^{g}$

$\frac{\delta L}{\delta i_{t}}=\gamma\left(i_{t}-i_{t-1}\right)-\lambda_{\mathbf{2}} \theta=0 \Leftrightarrow \lambda_{\mathbf{2}}=\frac{\gamma\left(i_{t}-i_{t-1}\right)}{\theta}$

Then substituting the value of both $\lambda_{1}$ and $\lambda_{2}$ into the second first order condition we get an equation for the rate of interest:

the divine coincidence as a proposition that can be understood and tested in terms of variances: the smaller is the variance of the inflation gap, the smaller is the variance of the output gap.

${ }^{12}$ Woodford and Giannoni (2003), p.3, also state: "The present theory implies not only that price stability should matter in addition to stability of the output gap, but also that, at least under certain circumstances, inflation stabilization eliminates any need for further concern with the level with the level of real activity....the time varying efficient level of output is the same as the level of output that eliminates any incentive for firms on average to either raise or lower prices." 


$$
\begin{aligned}
& \frac{\delta L}{\delta y_{t}^{g}}=y_{t}^{g}+\alpha \lambda_{\mathbf{1}}-\lambda_{\mathbf{2}}=0 \Leftrightarrow y_{t}^{g}+\alpha \beta \pi_{t}^{g}-\frac{\gamma\left(i_{t}-i_{t-\mathbf{1}}\right)}{\theta}=\mathbf{0} \\
& \Leftrightarrow i_{t}=i_{t-\mathbf{1}}+\frac{\theta \alpha \beta}{\gamma} \pi_{t}^{g}+\frac{\theta}{\gamma} y_{t}^{g}
\end{aligned}
$$

Eq. (11) is an optimal interest rate rule commonly known as a Taylor rule equation. It states that the difference between the actual real rate of interest from its natural level $\left(r_{i}-r_{n}\right.$ or $\left.r_{t}^{g}\right)$ is proportional to output gap or the nominal interest gap is proportional to the inflation and output gaps ( $\pi_{t}^{g}$ and $y_{t}^{g}$ respectively). ${ }^{13}$ Accordingly when the actual rate of inflation is equal to its target $\left(\pi_{1} i=\pi^{\mathbf{T}} T\right)$ and given the 'divine coincidence', the level of output is equal to its natural level $\left(y_{i}=y_{n}\right)$; then the actual rate of interest is also at its equilibrium or natural level $\left(r_{i}=r_{n}\right)$. This is exactly the sort of result that Knut Wicksell had suggested long ago.

The interest rate equation jointly with the Phillips curve and the aggregate demand (IS) function completes the system required to prove the stability property. This can be seen by rewriting the corresponding system comprised of Eqs. (3, 4, and 11) as a system of differential equations,

$\dot{y}^{g}=-\varphi \dot{r}$

$\tilde{\pi}=\alpha y^{g}$

$\dot{r}=\frac{\theta \alpha \beta}{\gamma} \pi^{g}+\frac{\theta}{\gamma} y^{g}$

Substitution of the interest equation $(\tilde{r})$ into the output gap equation $\left(y^{\tau} g\right)$ reduces the system to two differential equations which can be expressed in matrix form as,

$\left[\begin{array}{l}\dot{y} \\ \dot{x}\end{array}\right]=\left[\begin{array}{cc}-\varphi \frac{\theta \alpha \beta}{\gamma} & -\varphi \frac{\theta}{\gamma} \\ \alpha & \mathbf{0}\end{array}\right]\left[\begin{array}{c}y \\ \pi\end{array}\right]+\left[\begin{array}{c}\varphi \theta \alpha \\ \gamma\left(\beta \pi^{T}+y_{n}\right) \\ -\alpha y_{n}\end{array}\right]$

\footnotetext{
${ }^{13}$ Here we assume that monetary policy responds the current inflation and output gaps. In some specifications monetary policy responds in the first instance only to the inflation gap and only in a second stage, does it respond to the output gap.
} 
The stability of the system is provided by the Jacobian matrix. Since the determinant of the Jacobian matrix is positive $(\varphi \alpha \theta / \gamma>0)$ and the trace is negative $\left(-\varphi \frac{\theta \alpha \beta}{\gamma}<\mathbf{0}\right)$, the $2 \times 2$ system is stable.

\section{The FFITs as open economies}

The economies that have formally adopted FFIT regimes are different in terms of size and development, productive structure, and export base. Nonetheless, they share one common feature. They have become increasingly open over time since before the adoption of FFIT regimes. Figure 1 shows for FFIT developed and developing economies, the composition of trade in GDP, weighted tariff rates, the participation of private financial flows in GDP and the degree of financial openness measured by the Chinn-Ito index, 10, 5 years before and 5 and 10 years following the adoption of inflation targeting.

On average ten years prior to the adoption of a FFIT regime, the participation of trade (exports plus imports) in GDP for all economies included in our sample reached $56 \%$. Ten years following the adoption of inflation targeting it increased to $67 \%$. For the same period the weighted tariff rate declined from $8.2 \%$ to $5.6 \%$. Similarly private financial flows which stood at $2.5 \%$ of GDP ten years prior to the adoption of inflation targeting expanded to attain $3 \%$ of GDP five years after.

Finally, the degree of financial openness (Chinn-Ito index) rose for all economies in the sample after the instauration of FFIT regimes. In the case of developed countries the standardized index measured on scale from 1 to 100 took values of 53 and 83, 5 and 10 years prior to the adoption of FFIT attaining a maximum of 100 thereafter. For developing countries, the Chinn Ito index had an average value of 3, at the time of the adoption of the FFIT and 56 a decade after.

The fact that the FFIT economies are open economies in terms of trade and finance and the broad majority of these are developing economies underscores the importance of the exchange as a transmission mechanism of monetary policy and also of external shocks (Svensson, 2000).

In a closed economy, the decisions of economic policy are transmitted through aggregate demand and the associated expectations channels. Changes in the rate of interest or even monetary aggregates directly impact on aggregate demand via changes in consumption, investment and imports. ${ }^{14}$ In turn variations in aggregate demand impinge directly on the rate of inflation if the economy is at full employment, which is what the conventional model presumes with the notion of the Divine Coincidence, or indirectly by altering the bargaining position of workers. In addition, changes in expectations can also have an effect on inflation 'via wage and price setting behavior' (Svensson, Ibid).

\footnotetext{
${ }^{14}$ Evidence suggests that interest rates affect housing investment, but do not have a major impact on private investment, which tends to respond to quantities rather than cost of capita measures. See, for example, Fazzari (1993).
} 
Figure 1: Real and financial indicators of the degree of openness of the FFIT economies (ten and five years prior to the adoption of inflation targeting and five and ten years after) (exports and imports $(\mathrm{X}+\mathrm{M})$ as $\%$ of GDP, weighted tariffs rates, private capital flows as \% of GDP and the Chinn-Ito index of financial openness).

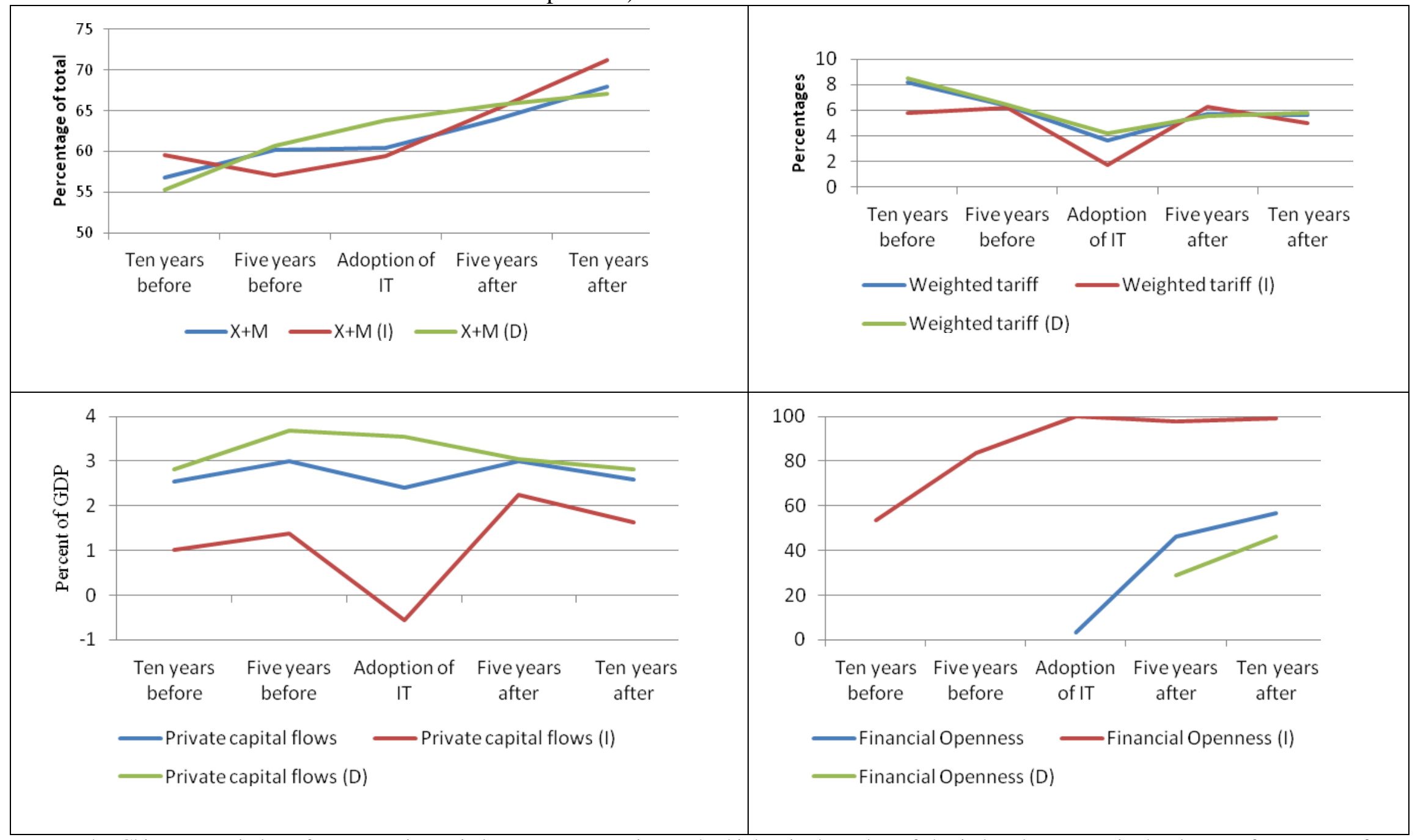

Note: The Chinn-Ito an index of openness in capital account transactions. The higher is the value of the index the greater is the degree of openness of an economy to cross-border capital transactions.

Source: Authors' own computations on the basis of World Bank (2013); Chinn-Ito (2013). 
In an open economy the monetary policy transmission mechanism is more complex. Changes in the nominal exchange rate affect the rate of inflation directly through their effect on the price in domestic currency of imported final goods. At the same time, the rate of exchange affects has an influence on the cost of locally goods produced locally through changes in domestic price of imported inputs.

Changes in the nominal exchange rate also operate indirectly on the rate of inflation. To the extent that a nominal exchange rate variation affects the real exchange rate, it alters the relative price of traded-to-non traded goods reinforcing the aggregate demand channel. An increase in the relative price of traded-to-non-traded goods (a devaluation in real terms), will make locally produced goods more competitive and will thus increase the incentives to shift resources towards the production of domestic goods. As a result domestic absorption (internal demand) will increase putting pressure on prices if the economy is close to full employment.

An additional transmission channel for the exchange rate is the balance sheet channel. Changes in the exchange rate affect the position in assets and liabilities of firms, households and also of the government. The balance sheet channel can offset partly or completely the expansionary effects of a depreciation, depending on the importance of assets in foreign currency held by the different sector of the economy. A depreciation of the currency increases the stock of external debt as well as interest service and thus exerts a negative effect on aggregate demand. In other words, changes in the exchange rate may have a significant impact on income distribution and may turn to be contractionary.

Moreover, the exchange rate also operates as a transmission vehicle for foreign disturbances and external demand shocks. This channel is relevant because of the high degree of international integration among economies, and the strong economic dependence of developing economies on external markets and developed country resources. This transmission mechanism is even more significant depending on the extent to which the exchange rate behaves like an asset price (i.e., "when it responds to potential capital gains or losses in forward markets" Eatwell and Taylor, 2000, p. 63).

According to the logic of inflation targeting, the level or value of the exchange rate should not be, in principle, a main concern for monetary policy. In fact, inflation targeting proponents argue that a flexible exchange rate regime is a 'requirement for a well functioning inflation targeting regime.' This view responds to the fact that in a world of full capital mobility, the monetary authorities cannot maintain an independent monetary policy and a stable exchange rate at the same time, the so-called Impossible Trinity or Trilemma. ${ }^{15}$ More importantly, since the main policy instrument, the rate of interest affects both the inflation rate and the exchange rate, worrying about the exchange rate would imply that the authorities are trying to manage two targets with one instrument.

\footnotetext{
${ }^{15}$ Note that the Trilemma does not apply to the Hegemonic country that holds the global reserve currency. Also, under certain circumstances, when the balance of payments constraint is not binding, developing countries are relatively free of the constraints imposed by the Trilemma.
} 
Table 3: Foreign exchange intervention index and regression analyses between the change in international reserves $\left(\triangle R E S_{t}\right)$ and the real exchange rate gap $\backslash\left(R E R \rrbracket{ }_{\downarrow} t^{\top} g\right)$ for FFIT economies

\begin{tabular}{|c|c|c|c|c|c|c|c|}
\hline & \multicolumn{2}{|c|}{ FEIS } & \multicolumn{5}{|c|}{\begin{tabular}{c}
\multicolumn{2}{c}{ Regression analysis } \\
$\Delta R E S_{t} \quad($ dependent variable $)$
\end{tabular}} \\
\hline & & & & & $\mathrm{AR}(1)$ & No. Obs & $\overline{R^{2}}$ \\
\hline & $\begin{array}{l}\text { Before } \\
\text { FFIT }\end{array}$ & $\begin{array}{l}\text { After } \\
\text { FFIT }\end{array}$ & $\begin{array}{l}\text { Before } \\
\text { FFIT }\end{array}$ & $\begin{array}{l}\text { After } \\
\text { FFIT }\end{array}$ & $\begin{array}{c}\text { Before FFIT/ } \\
\text { After FFIT }\end{array}$ & $\begin{array}{c}\text { Before } \\
\text { FFIT/After FFIT }\end{array}$ & $\begin{array}{c}\text { Before FFIT/ } \\
\text { After FFIT }\end{array}$ \\
\hline Australia & $\begin{array}{l}0.79 \\
0.03\end{array}$ & $\begin{array}{l}0.73 \\
0.02\end{array}$ & $\begin{array}{c}1.78 \\
(2.01)\end{array}$ & $\begin{array}{l}-0.14 \\
(-0.25)\end{array}$ & $\begin{array}{l}0.75(7.13) / \\
0.66(7.5 * *)\end{array}$ & $47 / 78$ & $0.54 / 0.42$ \\
\hline Brazil & $\begin{array}{l}0.72 \\
0.29 \\
\end{array}$ & $\begin{array}{l}0.61 \\
0.59\end{array}$ & $\begin{array}{r}1.05 \\
(9.55) \\
\end{array}$ & $\begin{array}{c}1.22 \\
(7.70 * *)\end{array}$ & $\begin{array}{l}0.89(15.05) / \\
0.66(6.90 * *)\end{array}$ & $73 / 53$ & $0.83 / 0.77$ \\
\hline Canada & $\begin{array}{l}0.88 \\
0.88\end{array}$ & $\begin{array}{l}0.67 \\
0.69\end{array}$ & $\begin{array}{c}-1.72 \\
(-0.46)\end{array}$ & $\begin{array}{c}0.06 \\
(0.13)\end{array}$ & $\begin{array}{c}0.67(5.53 * *) \\
/ 0.58(6.56 * *)\end{array}$ & $40 / 87$ & $0.36 / 0.32$ \\
\hline Chile & $\begin{array}{l}0.70 \\
0.54\end{array}$ & $\begin{array}{l}0.64 \\
0.52\end{array}$ & $\begin{array}{c}0.65 \\
(1.66)\end{array}$ & $\begin{array}{c}-0.08 \\
(-0.24)\end{array}$ & $\begin{array}{c}0.82\left(12.3^{* *}\right) / \\
0.72\left(7.28^{* *}\right)\end{array}$ & $74 / 52$ & $0.69 / 0.52$ \\
\hline Colombia & $\begin{array}{l}0.73 \\
0.72 \\
\end{array}$ & $\begin{array}{l}0.47 \\
0.46 \\
\end{array}$ & $\begin{array}{c}0.1 \\
(0.26) \\
\end{array}$ & $\begin{array}{c}0.36 \\
(1.97 * *) \\
\end{array}$ & $\begin{array}{l}0.84(8.9 * *) / \\
0.67(6.9 * *)\end{array}$ & $39 / 52$ & $0.66 / 0.59$ \\
\hline Czech Republic & $\ldots$ & $\begin{array}{l}0.66 \\
0.52\end{array}$ & $\ldots$. & $\begin{array}{c}1.39 \\
(2.81 * *)\end{array}$ & $0.67(6.45 * *)$ & 55 & 0.59 \\
\hline Ghana & $\begin{array}{l}0.52 \\
0.51 \\
\end{array}$ & $\begin{array}{l}0.83 \\
0.78 \\
\end{array}$ & $\begin{array}{c}0.02 \\
(0.13) \\
\end{array}$ & $\begin{array}{c}-0.42 \\
(-0.59) \\
\end{array}$ & $\begin{array}{l}0.70(8.8 * *) / \\
0.79(7.63 * *) \\
\end{array}$ & $83 / 43$ & $0.48 / 0.59$ \\
\hline Hungary & $\begin{array}{l}0.87 \\
0.85 \\
\end{array}$ & $\begin{array}{l}0.71 \\
0.70 \\
\end{array}$ & $\begin{array}{c}-1.29 \\
(-1.10) \\
\end{array}$ & $\begin{array}{c}-0.10 \\
(-0.18) \\
\end{array}$ & $\begin{array}{c}0.82(10.7 * *) / \\
0.63(4.88 * *)\end{array}$ & $54 / 41$ & $0.65 / 0.36$ \\
\hline Iceland & $\begin{array}{l}0.81 \\
0.61 \\
\end{array}$ & $\begin{array}{l}0.70 \\
0.65 \\
\end{array}$ & $\begin{array}{c}1.25 \\
(1.41) \\
\end{array}$ & $\begin{array}{c}0.61 \\
(1.02) \\
\end{array}$ & $\begin{array}{l}0.61(6.76 * *) \\
/ 0.56(4.3 * *) \\
\end{array}$ & $80 / 44$ & $0.41 / 0.37$ \\
\hline Israel & $\begin{array}{l}0.81 \\
0.31 \\
\end{array}$ & $\begin{array}{l}0.73 \\
0.69 \\
\end{array}$ & $\begin{array}{c}-0.81 \\
(-1.10) \\
\end{array}$ & $\begin{array}{c}-0.05 \\
(-0.15) \\
\end{array}$ & $\begin{array}{c}0.77\left(8.46^{* *}\right) / \\
0.83(17.3 * *)\end{array}$ & $66 / 61$ & $0.53 / 83$ \\
\hline Mexico & $\begin{array}{l}0.75 \\
0.70 \\
\end{array}$ & $\begin{array}{l}0.53 \\
0.55 \\
\end{array}$ & $\begin{array}{c}0.26 \\
(0.34) \\
\end{array}$ & $\begin{array}{c}0.39 \\
(1.68 * *)\end{array}$ & $\begin{array}{c}0.74\left(6.19^{* *}\right) / \\
0.72\left(6.83^{* *}\right)\end{array}$ & $44 / 47$ & $0.53 / 57$ \\
\hline New Zealand & $\begin{array}{l}0.81 \\
0.95 \\
\end{array}$ & $\begin{array}{l}0.73 \\
0.92 \\
\end{array}$ & $\begin{array}{c}-2.95 \\
(-2.46)\end{array}$ & $\begin{array}{c}1.82 \\
(3.81 * *)\end{array}$ & $\begin{array}{c}0.44 /(2.82 * *) / \\
0.72(10.1 * *)\end{array}$ & $35 / 91$ & $0.34 / 0.61$ \\
\hline Norway & $\begin{array}{l}0.84 \\
0.83 \\
\end{array}$ & $\begin{array}{l}0.71 \\
0.71 \\
\end{array}$ & $\begin{array}{c}-0.19 \\
(-0.22) \\
\end{array}$ & $\begin{array}{c}0.25 \\
(0.37) \\
\end{array}$ & $\begin{array}{c}9.22(0.73) / \\
0.64\left(5.38^{* *}\right) \\
\end{array}$ & $80 / 47$ & $0.52 / 0.39$ \\
\hline Philippines & $\begin{array}{l}0.82 \\
0.80\end{array}$ & $\begin{array}{l}0.72 \\
0.72 \\
\end{array}$ & $\begin{array}{c}0.52 \\
(0.51) \\
\end{array}$ & $\begin{array}{c}1.27 \\
(2.73 * *)\end{array}$ & $\begin{array}{l}0.60\left(6.56^{* *}\right) / \\
0.85\left(10.16^{* *}\right)\end{array}$ & $83 / 43$ & $0.35 / 0.79$ \\
\hline Poland & $\begin{array}{l}0.34 \\
0.37 \\
\end{array}$ & $\begin{array}{l}0.60 \\
0.59 \\
\end{array}$ & $\begin{array}{c}0.03 \\
(13.3) \\
\end{array}$ & $\begin{array}{c}1.38 \\
(3.44 * *) \\
\end{array}$ & $\begin{array}{c}0,84(13.3 * *) / \\
0.67(4.84 * *)\end{array}$ & $72 / 35$ & $0.71 / 0.63$ \\
\hline South Africa & $\begin{array}{l}0.85 \\
0.84 \\
\end{array}$ & $\begin{array}{l}0.56 \\
0.55 \\
\end{array}$ & $\begin{array}{c}0.74 \\
(0.02) \\
\end{array}$ & $\begin{array}{c}0.28 \\
(1.43 *) \\
\end{array}$ & $\begin{array}{l}0,51(4.9 * *) / \\
0.88(13.1 * *) \\
\end{array}$ & $75 / 51$ & $0.26 / 0.81$ \\
\hline Sweden & $\begin{array}{l}0.72 \\
0.73 \\
\end{array}$ & $\begin{array}{l}0.76 \\
0.76 \\
\end{array}$ & $\begin{array}{c}1.03 \\
(2.51) \\
\end{array}$ & $\begin{array}{c}0.71 \\
(1.79 * *)\end{array}$ & $\begin{array}{c}0.40(3.14 * *) / \\
0.79\left(10.6^{* *}\right)\end{array}$ & $55 / 71$ & $0.34 / 0.63$ \\
\hline United Kingdom & $\begin{array}{l}0.54 \\
0.81 \\
\end{array}$ & $\begin{array}{l}0.52 \\
0.89 \\
\end{array}$ & $\begin{array}{c}0.98 \\
(1.89) \\
\end{array}$ & $\begin{array}{c}0.99 \\
(2.91 * *)\end{array}$ & $\begin{array}{c}0.90(13.8 * *) / \\
0.78(2.91 * *)\end{array}$ & $47 / 80$ & $0.79 / 0.57$ \\
\hline
\end{tabular}

Note: The FFEIs columns include the computation of the statistics with the real and nominal exchange rate respectively. $* *$ and $*$ denote significant at the $95 \%$ and $90 \%$ level of confidence. An increase (decrease) in the real and nominal exchange rate refers to an appreciation (depreciation) of the national currency. All regression analyses included the standard diagnostics which are not presented for want of space. All regression were checked for basic goodness of fit indicators. All computations were performed using quarterly data.

Source: Authors' own computations on the basis of IMF (2013) 
Yet, in practice, due to the institutional openness of the economies that have adopted FFIT regimes, the importance of the exchange rate as a transmission mechanism and as a determinant of the level and composition of output, the value of the exchange rate matters. The central banks of FFITs are not indifferent to exchange rate movements and indeed intervene in foreign exchange markets.

This is illustrated in Table 3. It shows on a country-by-country basis before and after inflation targeting the reaction of foreign exchange reserves to changes in the real exchange rate (RER). This is captured by regressing the change in international reserves on the deviation of the real exchange rate from its trend.

In addition it also shows for the same periods and countries the degree of foreign exchange market intervention. This is measured by the statistic (FEIS= foreign exchange intervention statistic):

$F E I S=\frac{\sigma_{\Delta F o r e x \text { Re serves }}}{\sigma_{\Delta \text { Forex } \mathrm{Re} \text { serves }}+\sigma_{\text {ExchangeRae }}}$, where $\sigma=$ standard deviation and $\Delta=x_{t}-x_{t-4}$

The FEIS ranges between 0 , which reflects a pure float, to 1 which reveals that monetary authorities intervene to smooth out variations in the exchange rate. The FEIS was computed using both the real and the nominal exchange rate. As a benchmark value for the computations using the real exchange rate we use the value provided in Ostry et al. (2012), 0.73, which reflects the degree of intervention for emerging market economies that do not pursue an inflation targeting strategy and thus that do not adhere in principle to a floating exchange rate regime.

The results show that all foreign exchange intervention statistics (FEIS) are positive and with a few exceptions significantly different than the 0.73 benchmark. All countries whether developing or developed intervene in the foreign exchange markets. On average the exchange intervention statistic (using the real exchange rate) is 0.65 for the whole sample, 0.68 for developed countries and 0.62 for developing economies. While for the most part, the FEIS is lower in the period following the adoption of inflation, the differences between the FEIS before and after inflation targeting are also not significant. Finally, the evidence also underscores the fact that FFITs regimes take into account not only the real exchange rate but also the nominal exchange rate.

The fact that FFTI countries intervene in the foreign exchange rate markets and thus that none follows a float is compounded by the regression analyses. In more than half of the cases considered the deviation of the real exchange rate from its trend is statistically significant in explaining the change in the stock of foreign reserves.

\section{Introducing the open economy dimension in an inflation targeting framework}

The empirical evidence presented above is an indication that not only does the exchange rate matter, but that in fact, in terms of the conventional model presented before, it forms part of the loss function of FFIT central banks. Yet as will be shown below the introduction of the 
exchange rate in the central banks loss functions creates important complications for the management of monetary policy within an inflation targeting framework. In fact it can be shown that with a modified loss function, the core propositions of inflation targeting are inoperative that the practice of this monetary policy strategy leads to important policy dilemmas, even if one accepts the conventional model.

Assume that the Central Bank minimizes a loss function that includes in addition to the output and inflation gaps, and interest rate smoothing, the nominal exchange rate gap. Eq. (1) is thus modified to yield:

(13) $L=\left(y_{a}-y_{n}\right)^{2}+\beta\left(\pi_{t}-\pi^{T}\right)^{2}+\gamma\left(i_{t}-i_{t-1}\right)^{2}+\psi\left(e_{t}-e^{T}\right)^{2}$

Where, $e_{t}, e_{t}^{T}$ refer to the actual and target nominal exchange rate. In addition modify the respective constraints so as to include the nominal exchange rate in the Phillips curve and the real exchange rate in the aggregate demand (IS) equation:

(14) $\pi_{t}=E_{t} \pi_{t+1}+\alpha\left(y_{a}-y_{n}\right)+\omega E_{t} \Delta e_{t}$

(15) $y_{t}^{g}=-\varphi\left(i_{t}-E \pi_{t+1}\right)+E y_{t+1}^{g}+\theta r e r_{t}$

The first order conditions become respectively:

$\frac{\delta L}{\delta \pi_{t}}=\beta \pi_{t}^{g}-\lambda_{1}=\mathbf{0}$

$\frac{\delta L}{\delta y_{t}^{g}}=y_{t}^{g}+\alpha \lambda_{\mathbf{1}}-\lambda_{\mathbf{2}}=\mathbf{0}$

$\frac{\delta L}{\delta i_{t}}=\gamma\left(i_{t}-i_{t-1}\right)-\lambda_{\mathbf{2}} \theta=\mathbf{0}$

$\frac{\delta L}{\delta e_{t}}=\psi e_{t}^{g}-\lambda_{1} \omega=\mathbf{0}$

Setting the second Lagrangean multiplier $\left(\lambda_{1} 2\right)$ to 0 , and through successive substitution the value of first Lagrangean multiplier $\left(\lambda_{1} \mathbf{1}\right)$ is seen to be equal to the output, inflation and exchange rate gaps. The inflation gap $\left(\beta \pi_{t}^{g}\right)$ is not only equal to the opposite sign of the output gap but also to that of the exchange rate. Formally: 
(17)

$$
\begin{aligned}
& \lambda_{1}=\beta \pi_{t}^{g} \\
& \pi_{t}^{g}=-\frac{y_{t}^{g}}{\beta \alpha} \\
& \lambda_{1}=-\frac{\psi e_{t}^{g}}{\omega} \quad \Rightarrow \\
& \lambda_{1}=-\frac{y_{t}^{g}}{\alpha} \quad \pi_{t}^{g}=-\frac{\psi e_{t}^{g}}{\omega \beta}
\end{aligned}
$$

This implies that a lean against the wind policy is necessarily mediated, in an open economy, by movements in the exchange rate. As such when the rate of inflation is above target the central bank must implement a contraction in aggregate demand, so that the output gap is negative. It also must ensure simultaneously that the exchange rate moves in the right direction, that is, that it appreciates to permit the reduction of inflation (inflation enters as an argument in the Phillips curve besides appearing in the loss function). Thus the logic of the model implies that the exchange rate (in this particular case the appreciation of the exchange rate) is an instrument alongside aggregate demand to maintain the rate of inflation in line with its enunciated target.

Both the reduction in prices and the appreciation of the nominal exchange rate translate into an appreciation of the real exchange rate( rer $\left._{t}\right)$. Thus the reduction of inflation impacts negatively on output through the decline in aggregate demand and via the appreciation of the exchange rate (the external sector) which was required in the first place to reduce inflation. In this sense the monetary authorities face the dilemma of reducing inflation at the cost of a decline in competitiveness. This presumes that an appreciation does have a significant impact on competitiveness and does lead to an increase in imports (and probably to some decrease in exports) sufficient to constrain growth. The contractionary impact on output can only be compensated by expansionary fiscal policy if there is no external constraint. Note, however, that in the conventional model presented here this is not possible since the economy would be at potential output when inflation is at the target and the rate of interest is at the natural level. Hence, the role of fiscal policy, which was ignored in the closed version of the conventional model, must become relevant in the open economy case.

Further, once the exchange rate is introduced in the model achieving the Divine Coincidence is not a straightforward matter and can become a source of controversy. From Eq. (14) above it is clear that if, $\pi_{t}=E_{t} \pi_{t+1}$, the level of output would not be equal to its natural level, i.e., $y_{t}^{g}=0$. Indeed, even if the monetary authorities reach their inflation target, the output gap would still differ from zero. It would be equal to $\mathbf{I} \omega\left(E_{\mathbb{1}} t \boldsymbol{\Delta} e_{\downarrow} t\right)$. A reduction in the variance of output and inflation is always a possibility if $\pi_{t} \rightarrow \pi^{T}$ and $\uparrow \mid \boldsymbol{I} \omega\left(E_{\mathbb{1}} t \boldsymbol{\Delta} e_{\downarrow} t\right)$. The Divine Coincidence, in the open economy conventional model, requires thus two conditions $\pi_{t} \rightarrow \pi^{T}$ and $e_{t} \rightarrow e^{T}$. 
This is itself contradictory. Once again as with the lean against the wind proposition, achieving the Divine Coincidence requires an appreciation of the exchange rate and thus a worsening of the competiveness, which might undermine the very achievement of the Divine Coincidence. In an open economy The Divine Coincidence appears to be impossible even within the conventional model.

Once the exchange rate is introduced in the loss functions and in the Phillips and aggregate demand curves, it also appears in the interest rate rule of the Central Bank. Indeed, manipulation of the first order conditions provides two interest rate rules. The first is the same one as that for a closed economy in which the rate of interest is a function of its past value, the output and inflation gaps. According to the second rule, the interest rate is a function of its past value, the inflation and exchange rate gaps. Formally:

$$
\begin{aligned}
& i_{t}=i_{t-\mathbf{1}}+\frac{\theta \alpha \beta}{\gamma} \pi_{t}^{g}+\frac{\theta}{\gamma} y_{t}^{g} \\
& i_{t}=i_{t-\mathbf{1}}+\frac{\theta \alpha \psi}{\gamma \omega} e_{t}^{g}+\frac{\theta}{\gamma} y_{t}^{g}
\end{aligned}
$$

Both rules coincide only if the output gap maintains a given relation with the exchange rate gap (that is, if $\theta \psi / \gamma \omega e_{1} t^{\uparrow} g=\beta / \theta \pi_{1} t^{\uparrow} g$ ). In reality, there is no mechanism to ensure this equality and the most reasonable interpretation is that the Central Banks has two interest rate rules. More importantly since the divine coincidence does not apply once the exchange rate is introduced into the loss function, the inflation targeting framework implies necessarily that the Central Bank has one instrument to achieve three goals, low and stable inflation, full employment output and exchange rate stability and competitiveness.

Regarding stability since there are two interest rate rules there are also two possible solutions for stability. The first one using the interest rate rule without the exchange rate (Eq. 18) corresponds to that found for a closed economy. This is explained by the fact that the configuration of the Jacobian determinant is the same. A second possible solution consists in using the interest rule equation with the exchange rate (Eq. 18). In this case, the Phillips curve, the aggregate demand curve and the interest rule equation (Eqs. 14, 15 and 17) would be insufficient to assess the stability of the system. In fact it can be shown that the Jacobian determinant is equal to 0 and thus that the inflation and output gap equations are linearly dependent.

\section{A stylized representation of the practice of inflation targeting in open economies}

The inoperative nature of the three core propositions of inflation targeting in an open economy materializes in the way in which countries practice inflation targeting 'de facto.' To illustrate this point we analyze to what extent these three propositions (lean against the wind, the 
divine coincidence and stability) characterize FFIT countries' implementation of inflation targeting.

In order to assess whether FFIT countries do or do not lean against the wind we calculated the correlation coefficient over time between the inflation and the output gap as postulated by Eqs. ( $6 \& 17$ ) above. ${ }^{16}$ A negative and statistically significant coefficient provides an indication that countries practice monetary policy counter-cyclically. ${ }^{17}$ For analytical purposes we also provide the correlation coefficients between the inflation and the nominal exchange rate gaps and that between the output and nominal exchange rate gaps.

The second proposition, the divine coincidence, is tested empirically by the correlation in the variances of the output and inflation gaps. A positive and statistically significant correlation between both variances suggests that the Divine Coincidence hypothesis cannot be refuted. As the actual rate of inflations narrows its deviation with respect to the inflation gap, the actual level of output tends towards its trend level. As with the case of the lean-against-the-wind, we also included the exchange rate in our computations.

Finally, we tried to test for stability of the inflation targeting model comprised by Eqs. $(14,15)$ and $\mathrm{Eq} 18$ (the interest rate rule without the exchange rate) by solving it as a system and seeing whether the estimates parameters comply with the stability conditions of a positive Jacobian determinant and a positive trace.

The results show that the more than half of the correlation coefficients between the inflation and the output gap, for the countries for which there is available data, are positive and significant (Column (1) Table 4 above). In other words, keeping in mind that the policy instrument is the output gap, FFIT countries in their vast majority do not seem to follow the 'lean against the wind' optimal monetary strategy consisting in contracting demand below capacity whenever inflation is above its targeted value, and vice versa when inflation is below its target.

\footnotetext{
${ }^{16}$ Note that the output gap is computed as an average of the actual output method, following conventional approaches of measuring it, and assuming that it is determined by supply side forces as in the conventional model. The results are even more blurred if potential output hysteresis is present, and it is affected by demand management policies.

17 The statistical significance of the correlation coefficient was determined on the basis of the formula: $\rho=\frac{r(\sqrt{n-2})}{\sqrt{1-r^{2}}}$ where $r$ is the simple correlation coefficient and $n$ the number of observations. $\rho$ follows a student-t distribution.
} 
Table 4: The core propositions of inflation targeting in practice for FFIT economies

\begin{tabular}{|c|c|c|c|c|c|c|c|c|}
\hline \multirow{3}{*}{ Country } & \multirow{2}{*}{\multicolumn{3}{|c|}{ Lean against the wind }} & \multirow{2}{*}{\multicolumn{3}{|c|}{ The divine coincidence }} & \multicolumn{2}{|c|}{ Stability } \\
\hline & & & & & & & & \\
\hline & $\begin{array}{c}\pi_{t}^{g} \cdot y_{t}^{g} \\
(1) \\
\end{array}$ & $\begin{array}{c}\pi_{t}^{g}, e_{t}^{g} \\
(2) \\
\end{array}$ & $\begin{array}{c}y_{t}^{g} \times e_{t}^{g} \\
(3) \\
\end{array}$ & 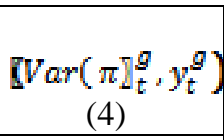 & 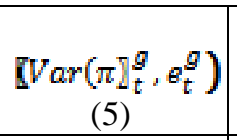 & $\begin{array}{c}\left.\varangle \operatorname{Var}(y]_{t}^{g}, e_{t}^{g}\right) \\
(6)\end{array}$ & $\begin{array}{c}\text { Trace } \\
\text { J } \\
(7) \\
\end{array}$ & $\begin{array}{c}\text { DET } \\
\text { J } \\
(8) \\
\end{array}$ \\
\hline Armenia & $\ldots$ & 0.03 & $\cdots$ & $\ldots$ & 0.04 & $\cdots$ & $\cdots$ & $\cdots$ \\
\hline Australia & $-0.20 *$ & $-0.30 * *$ & $0.33 * *$ & $0.40 * *$ & $-0.35 * *$ & $0.24 * *$ & $<0$ & $>0$ \\
\hline Brazil & -0.13 & $-0.45^{* *}$ & $0.32 * *$ & $-0.90 * *$ & $0.72 * *$ & $-0.77 * *$ & $>0$ & $<0$ \\
\hline Canada & 0.10 & $0.28 * *$ & 0.17 & $0.44 * *$ & 0.18 & $0.72 * *$ & $<0$ & $<0$ \\
\hline Chile & $0.31 * *$ & 0.02 & $0.32 * *$ & $0.90^{* * *}$ & -0.18 & -0.15 & $<0$ & $>0$ \\
\hline Colombia & $0.48 * *$ & 0.07 & $0.38 * *$ & $0.59 * *$ & 0.08 & 0.15 & $<0$ & $>0$ \\
\hline Czech Republic & 0.02 & 0.18 & $0.29 * *$ & 0.16 & $-0.64 * *$ & $0.30 * *$ & $>0$ & $<0$ \\
\hline Ghana & $\ldots$ & -0.37 & $\cdots$ & $\ldots$ & $-0.86 * *$ & $\cdots$ & $\cdots$ & $\cdots$ \\
\hline Guatemala & $0.44 *$ & $\ldots$ & $\ldots$ & $-0.67 * *$ & $\ldots$ & $\ldots$ & $>0$ & $<0$ \\
\hline Hungary & $0.37 * *$ & 0.13 & 0.24 & $-0.69 * *$ & $-0.61 * *$ & $0.90 * *$ & $>0$ & $<0$ \\
\hline Iceland & $0.72 * *$ & $0.66 * *$ & $0.42 * *$ & $0.53 * *$ & $0.61 * *$ & 0.26 & $>0$ & $>0$ \\
\hline Indonesia & 0.07 & $\ldots$ & $\cdots$ & $-0.90 * *$ & $\ldots$ & $\cdots$ & $<0$ & $>0$ \\
\hline Israel & -0.18 & -0.01 & $0.27 * *$ & $0.75^{* *}$ & $0.20 *$ & $0.58 * *$ & $<0$ & $>0$ \\
\hline Mexico & -0.20 & -0.09 & $0.52 * *$ & $0.67 * *$ & $0.91 * *$ & $0.79 * *$ & $>0$ & $<0$ \\
\hline New Zealand & $0.20 * *$ & 0.02 & $0.61 * *$ & $0.26^{* *}$ & $-0.23 * *$ & $-0.17 *$ & $<0$ & $>0$ \\
\hline Norway & -0.20 & 0.07 & 0.11 & $-0.27 *$ & -0.21 & $0.26^{*}$ & $>0$ & $>0$ \\
\hline Peru & $0.23 *$ & $\ldots$ & $\ldots$ & $0.87 * *$ & $\ldots$ & $\ldots$ & $<0$ & $>0$ \\
\hline Philippines & 0.08 & -0.06 & 0.17 & $0.53 * *$ & $0.23 /-0.04$ & $-0.46^{* *}$ & $<0$ & $<0$ \\
\hline Poland & $0.43 * *$ & -0.01 & 0.15 & $0.28 * *$ & -0.19 & 0.04 & $<0$ & $>0$ \\
\hline Romania & & 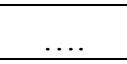 & 0.52 & .. & $\ldots$ & -0.34 & $\ldots$ & $\ldots$ \\
\hline Serbia & $0.41 * *$ & $\ldots$ & $\cdots$ & $\ldots$ & $\ldots$ & $\ldots$ & $>0$ & $<0$ \\
\hline South Africa & $0.51 * *$ & $-0.68 * *$ & -0.19 & $-0.73 * *$ & $0.49 * *$ & $-0.78 * *$ & $>0$ & $<0$ \\
\hline Korea, Rep. & $0.45^{* *}$ & $\ldots$ & $\ldots$ & $0.90 * *$ & $\ldots$ & $\ldots$ & $>0$ & $>0$ \\
\hline Sweden & $0.41 * *$ & 0.06 & $0.51 * *$ & $0.88 * *$ & $0.77 * *$ & $0.71 * *$ & $<0$ & $>0$ \\
\hline Thailand & $0.47 * *$ & $\ldots$ & $\ldots$ & $0.80 * *$ & $\ldots$ & $\cdots$ & $<0$ & $>0$ \\
\hline Turkey & 0.50 & $\cdots$ & $\ldots$ & $0.96 * *$ & $\cdots$ & $\ldots$ & $<0$ & $>0$ \\
\hline United Kingdom & 0.02 & -0.11 & $0.63 * *$ & $0.26 * *$ & $0.23^{*}$ & 0.04 & $>0$ & $>0$ \\
\hline
\end{tabular}

Note: $* *$ and $*$ denote significant at the $95 \%$ and $90 \%$ level of confidence. An increase (decrease) in the real and nominal exchange rate refers to an appreciation (depreciation) of the national currency. The inflation gap was computed as the difference between actual and target inflation (we used two inflation gaps in the case of target inflation tolerance bands). Target inflation was obtained on the basis of Hammond (2012) and on the basis of information provided by the respective central banks of the different countries. All regression analyses included the standard diagnostics which are not presented for want of space. All regression in the systems used to calculate the determinant and trace of the Jacobian matrix were checked for basic goodness of fit indicators. The cases that comply with the stability conditions positive Jacobian determinant and negative trace are highlighted in bold (columns 7 and 8). All computations were performed using quarterly data.

Source: Authors' own computations on the basis of IMF (2013). 
A second and interesting piece of evidence is that the relationship between the output gap and the exchange rate is positive (Column (2) Table 4). That is, a negative deviation of the exchange rate from its trend value (appreciation) is accompanied by a decline of output below capacity. And a positive deviation of the exchange rate from its trend value (depreciation) is accompanied by a rise of output above capacity. This result may reflect the fact that developing countries facing an external constraint, aggravated by competitiveness problems associated with an appreciated exchange rate, are forced to slowdown their economies. ${ }^{18}$

A third piece of evidence relevant to characterizing the practice of inflation targeting is that the majority of countries (59\% of the total) pass the Divine Coincidence test as shown by the positive and significant correlation between the variance of the output and inflation gaps. This is consistent with the evidence presented in favor of inflation targeting regimes, namely that that the inflation rate and its variability in lower in the majority of the cases in the post-FFIT relative to the pre-FFIT period.

An analysis of the evolution of inflation for all FFTI economies shows that this is indeed the case. The median pre and post FFIT rate of inflation reached $10 \%$ and $4 \%$ for all 27 countries, $4 \%$ and $2 \%$ for the developed group, and $8 \%$ and $5 \%$ for the developing economies. This result is generally presented as evidence of the success of FFIT regimes. As well, a test of differences in variance for the inflation rate for each of the 27 countries shows that $81 \%$ experienced lower inflation variability in the post-FFIT relative to the pre-FFIT period (See Figure $4 \mathrm{~b}$ and $4 \mathrm{c}$ and annex for detailed computations by country).

However, it is difficult to attribute this to the implementation of inflation targeting since the empirical evidence shows that the majority of the time most FFIT economies do not stay within the announced inflation target range (or near the announced point target for those economies that do not have an explicitly announced inflation range). On average FFIT countries stay on target on average $40 \%$ of the time. Also, several countries that do not adopt a FFIT also had a reduction in inflation levels which may be attributed to other causes beyond central bank policies, like subdued wage resistance and increasing external competition.

A more detailed analysis is provided in Figure 1d, which shows a histogram with the abscissa representing the percentage of the time FFIT countries stay within the announced inflation target and the ordinates representing the number of countries. According to Figure 2, only 6 out of the 27 FFIT countries (22\%) have managed to stay within the target range for more than $50 \%$ of the time and only one has complied with the target more than $70 \%$ of the time.

\footnotetext{
${ }^{18}$ Note that there is a vast literature on the positive effects of devaluation on economic growth (e.g. Rodrik, 2008). We do not necessarily suggest that our results corroborate that proposition. Note that the vast majority of studies that find a positive relation between real depreciation and economic growth are very sensitive to both the sample of countries, which may imply sample selection bias, and the measure of devaluation, which is often taken from deviations from Purchasing Power Parity. Our only suggestion is that the exchange rate is connected more to real phenomena associated ultimately with the management of the balance of payments, than with anti-inflationary policies.
} 
Figure 2: Selected indicators on FFIT performance and the inflation rate and variability for the world

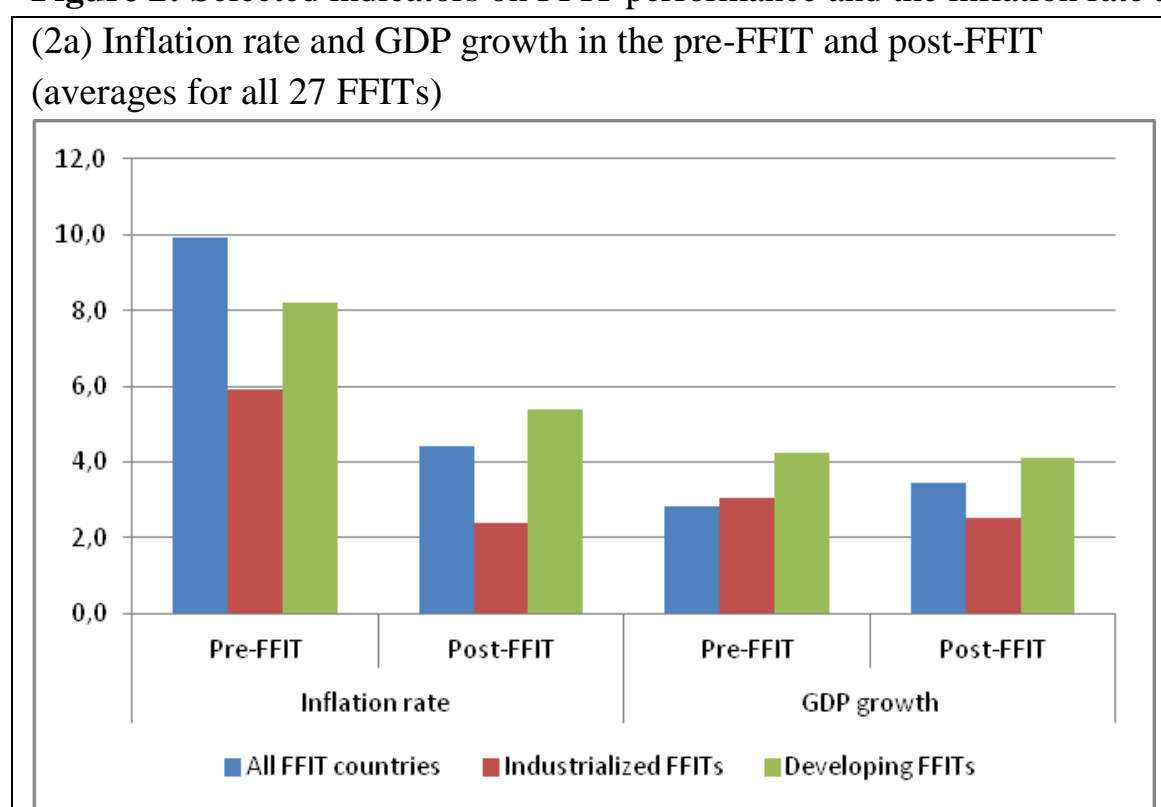

(2b) Percentage of world countries that experienced lower inflation rate and inflation variability in the period 1996-2012 relative to $1980-1995$

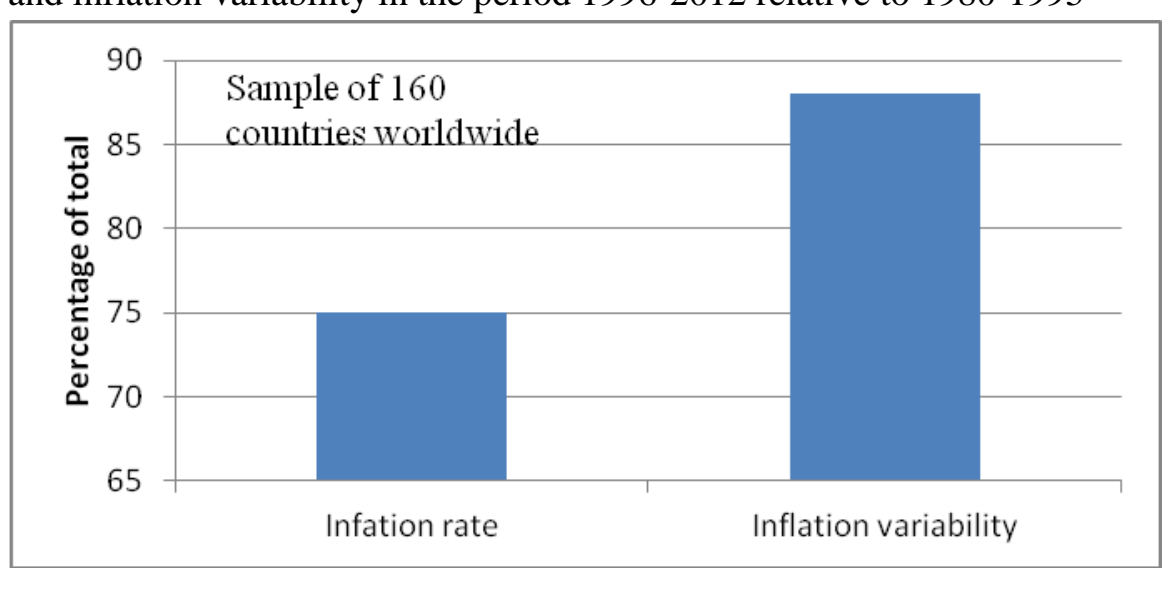

(2c) Percentage of FFIT countries that have reduced the variability in inflation, GDP growth, nominal and real exchange rates in the postFFIT relative to the pre-FFIT period

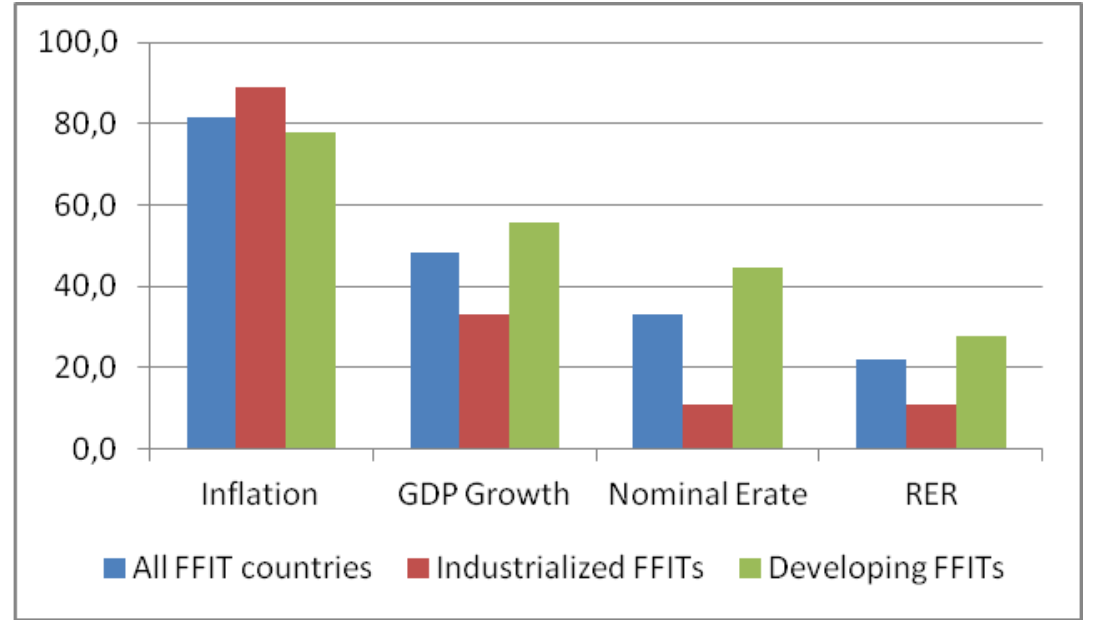

(2d) Histogram showing the percentage of time that FFIT countries stay 'within and on target'

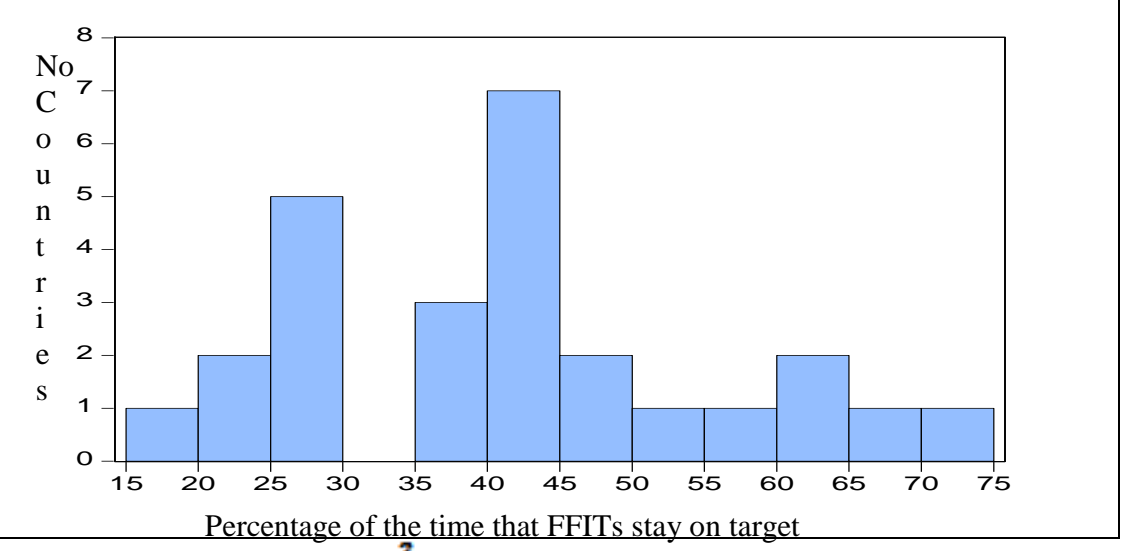

Percentage of the time that FFITs stay on target

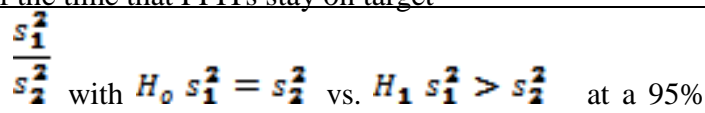

Source: Authors'own computation on the basis of IMF financial statistics data. Note: The F test was computed as F= $\overline{s_{2}^{2}}$ with $H_{0} s_{1}^{2}=s_{2}^{2}$ vs. $H_{1} s_{1}^{2}>s_{2}^{2} \quad$ at a $95 \%$ confidence level. 
Rather than responding to inflation targeting practices the occurrence of Divine Coincidence is due to two unrelated phenomena. On the one hand countries across the witnessed a reduction in the inflation levels and their variability, with independence of their monetary policy regimes, from the middle of the 1990s onwards which happens to coincide with the adoption of inflation targeting in all 27 countries of the sample. An analysis of inflation behavior for a sample of 160 counties worldwide, using quarterly data from 1980 to 2012, shows that $75 \%$ of the countries had a lower rate of inflation in the period 1996-2012 relative to 1980-1995. Similarly more than $80 \%$ of the countries in the sample show lower inflation variability in the latter relative to the former period.

On the other hand, FFIT's countries managed in the majority of cases to narrow the variance of the output and exchange rate gap jointly (Columns 4 and 6, Table 4). In light of the evidence presented in an earlier section, this perhaps indicates that countries narrowed the output gap through foreign exchange interventions.

Jointly with the fact that the relation between the inflation and exchange rate gap is mostly insignificant these findings (Column (3), Table 4) provide an indication that the tendency of all the FFIT economies to intervene in the foreign exchange markets discussed above, rather than being driven by price considerations, responds to real factors (the deviation of output from its trend level). ${ }^{19}$ More precisely we could even argue that the evidence presented indicates that the interventions in the foreign exchange market appear to be independent of the course and evolution of inflation, but not of the evolution of output. Further, it seems reasonable to assume that output considerations are in many cases related to balance of payments conditions. In other words, when faced with an external constrain central banks maybe forced to allow the currency to depreciate and end up missing the inflation target.

This de facto dichotomy between inflation and the exchange rate can create important policy dilemmas for the monetary authorities in a context of a simultaneous increase in inflation and appreciation of the currency. The rise in inflation requires an increase in the monetary policy rate if indeed inflation is caused by excessive demand, as it is presumed in the conventional model, but the appreciation of the currency (which is accompanied by a level of output below capacity, i.e., excess capacity) demands the opposite policy action (a decline in the rate of interest). This type of policy dilemma explains the reason why when both events (inflation and appreciation) occur Central Banks tend to miss their inflation target (they cannot at the same time increase and decrease the rate of interest.

Also this type of dilemma can perhaps also be part of the explanation about the mixed evidence for FFIT countries in terms of growth performance. On a country by country basis, 15 countries of the entire sample (55\% of the total) achieved a higher growth rate in the post-FFIT period. For the sub sample set of developing and developed countries, 3 and 10 (or 33\% and 53\% or each) economies experienced higher rates of growth in the post FFIT period. Similar results

\footnotetext{
${ }^{19}$ Arguably, the lack of correlation between the exchange rate and inflation gaps may reflect the fact that passthrough effects are generally lower in the world, and hence the effects of exchange rate variability on domestic prices has been attenuated (Frankel et al, 2012). This may reflect lower wage resistance from workers in the context of globalization. That is, depreciation does not lead to wage increases, and higher inflation as it did in the 1970s.
} 
are obtained for GDP variability using a difference in variance test on a country-by-country basis (See figures $2 \mathrm{a}$ and $2 \mathrm{c}$ above). Note, however, that the rates of growth have accelerated in many countries for reasons that are orthogonal to the monetary regime. For example, there is strong evidence supporting the notion that in Latin America the easing of the external constraint associated with a positive terms of trade shock since 2003 is correlated with the growth performance. Equally many countries have been affected by the Global Crisis that started in 2008, irrespective of their monetary regimes.

Finally, regarding the third core property of stability, the evidence shows that more than half of the countries (54\%) of the countries fail to corroborate it. In other words, the target rate of inflation does not appear to be part of a stable equilibrium configuration. ${ }^{20}$

As a general remark it is worth noticing that if one abandons the conventional model assumptions regarding the existence of a supply constrained potential output, with the concomitant notion of a natural rate of unemployment for which there is little evidence, ${ }^{21}$ and the notion that inflation is essentially demand driven, then the very idea of the three core properties of inflation targeting collapse, even in the case of a closed economy, for there would be no such thing as an output gap. Moreover, in an open economy, without a natural rate of unemployment or a potential level of output, the reasons to expect that a central bank could achieve several targets, full employment, price stability and external competitiveness with only one instrument, the rate of interest, are even less plausible.

This indicates that central banks with broader policy goals must coordinate with domestic fiscal authorities the management of domestic demand, and that other instruments must complement monetary and fiscal policy in order to achieve all the goals. Industrial policies, import and price management, as well as other income policies which used to be part of the box of tools of developmental governments should not be excluded, a priori, on the basis of a theoretical model that presents, even if one accepts its limited logic, inherent contradictions and significant policy problems.

\section{Concluding remarks}

As we saw the justification for inflation targeting rests on the closed economy model propositions that central banks lean against the wind, the belief in the Divine Coincidence suggesting that if the rate of inflation is around its target then output will be at the full employment level, and that following any disturbance to its initial conditions the system has a tendency to move towards its equilibrium. All these propositions are highly questionable from a theoretical point of view for an open economy, and are not clearly supported by the evidence.

The strategy adopted in this paper was to analyze whether those three propositions could be sustained in the actual countries that implement a full-fledged inflation targeting (FFIT) regime. It is noted that even within the mainstream model, once open economy considerations

\footnotetext{
${ }^{20}$ These results represent only a first approximation at the stability issue under inflation targeting.

${ }^{21}$ For the discussion of the irrelevance of the natural rate hypothesis see Galbraith (1997). For the empirical failure of the natural rate hypothesis in the American economy see Fair (2000).
} 
are introduced, the main propositions (lean against the wind, Divine Coincidence, and stability), based on the evidence on the 27 countries that have explicitly implemented a FFIT regime, do not hold in the real world. Moreover, these countries are open economies and are fundamentally concerned by the evolution of the external sector and the exchange rate as proven by their interventions in the foreign exchange markets and external sector considerations can have hierarchical priority over other policy goals. The trade-offs faced by central banks in open economies are significantly more complex than those suggested by the New Consensus model, and reliance on the FFIT regime should be taken with extreme caution, given the unreliability of its empirical results. 


\section{References}

Arestis, P. (2009) New Consensus Macroeconomics: A Critical Appraisal. Levy Economics Institute, Working Paper No 564.

Adler, G. \& Tovar C. Foreign Exchange Intervention: A Shield Against Appreciation Winds?. IMF Working Paper WP/11/165.

Amato, J.D \& Laubach, Th. The Value of Interest Rate Smoothing: How the Private Sector Helps the Federal Reserve. Economic Review, Federal Reserve Bank of Kansas City, issue Q III, pages 47-64.

Ainzeman, J., Hutchinson, M., Noy, I. (2008) Inflation Targeting and Real Exchange Rates in Emerging markets. NBER Working Paper Series. WP 14561

Angeriz, a. and Arestis, Ph. (2007) Assessing the Performance of 'Inflation targeting Lite' Countries, Vol.30, N.11, 1621-1645.

Arestis, Ph. and Sawyer, M. (2008) A critical reconsideration of the foundations of monetary policy in the new consensus macroeconomics framework. Cambridge Journal of Economics 2008, 32, 761-779.

Bernanke, B.S. and Woodford, M. Eds. (2005) The Inflation Targeting Debate. NBER. Chicago: University of Chicago Press.

Bernanke, B.S., Laubach, Th., Mishkin, F.S., Posen, A.S. (1999) Inflation Targeting. Lessons from the International Experience. Princeton: Princeton University Press.

Blanchard, O. (2006) Monetary Policy; Science or Art? Panel discussion, presented at IMonetary Policy: A Journey from Theory to Practice. An ECB colloquium held in honor of Otmar Issing, March 2006

Blanchard, O \& Gali, J. (2005), Real wage rigidities and the New Keynesian Model", NBER WP 11806, November 2005.

Cecchetti, S.G. and Kim J. (2006) Inflation Targetting, Price Path Targeting, and Output Variability (2005) in Bernanke, B.S. and Woodford, M. Eds. The Inflation Targeting Debate. NBER. Chicago: University of Chicago Press. 173-195.

Clarida, R., Galí, J. and Gertler, M. (1999) The Science of Monetary Policy: A New Keynesian Perspective. Journal of Economic Literature Vol XXXVII, 1661-1707.

Fair, R. (2000) Testing the NAIRU model for the United States, Review of Economics and Statistics, 82(1), pp. 64-71. 
Frankel, J., Parsley, D. and Wei, S-J. (2012) Slow Pass-through Around the World: A New Import for Developing Countries?, Open Economies Review, Springer, 23(2), pp. 213-51.

Galbraith, J. K. (1997) Time to Ditch the NAIRU, Journal of Economic Perspectives, 11(1), pp. 93-108.

Granville, B. \& Mallick S. Exchange rate shocks and monetary policy in Russia. Miemo.

Hammond, G (2912) State of the art of inflation targeting -2012. Handbook N. 29. Centre for Central Banking Studies. Bank of England.

IMF (2013) International Financial Statistics. http://elibrary-data.imf.org/

Jonas, J. and Mishkin, F.S. (2005) Inflation Targeting in Transition Economies: Experience and Prospects, in in Bernanke, B.S. and Woodford, M. Eds. The Inflation Targeting Debate. NBER. Chicago: University of Chicago Press. 353-413.

Kamil, H. (2008) Is Central Bank Intervention Effective Under Inflation Targeting Regimes? The Case of Colombia. IMF Working Paper WP/08/88.

Lam, J.P. (2010) The Importance of Commitment in the New Keynesian Model. Mimeo.

McCombie, J.S: and Thirlwall, A.P. (1999) Growth in an International Context. A Post Keynesian View. In Foundations of International Ecoomics. Post Keynesian Perspectives. Eds. Deprez, J. and Harvey, J.T. New York: Routledge.

Ncube, M. \& Ndou E. (2011) Inflation Targeting, Exchange rate Shocks and Output: Evidence from South Africa. African Development Group. Working paper Series. WP No. 134.

Ostry, J. O., Ghosh, A.R. \& Chamon, M. (2012) Two targets, Two instruments: Monetary and Exchange Rate Policies in Emerging Market Economies. IMF Staff Discussion Note. February 29, 2012.

Roger, S. (2009) Inflation targeting at 20: Achievments and Challenges. IMF Working paper $\mathrm{WP} / 09 / 236$.

Rochon, L.P. \& Setterfield, M. (2007) Post Keynesian interest rate rules and macroeconomic performance: a comparative evaluation http://www.univ-paris13.fr/cepn/IMG/pdf/Texte_Rochon_100409.pdf

Rodrik, D. (2008) "The real exchange rate and economic growth," Brookings Papers on Economic Activity, 2, PP. 365-412.

Sack, B. \& Wieland, W. (1999) Interest Rate Smoothing and Optimal Monetary Policy: A Review of Recent Empirical Evidence. Mimeo. 
Setterfield, M. (2006) Is inflation targeting compatible with Post Keynesian economics? Journal of Post Keynesian Economics. Vol. 28, No. 4. Pp. 653-671.

Svensson, L. (2007) Inflation Targeting. Mimeo for The New Palgrave Dictionary of Economics, $2^{\text {nd }}$ edition, edited by Larry Blum and Durlauf Steven.

Svensson, L. (2004) Comentary. In, Inflation Targeting: Prospects and Problems. Federal Reserve Bank of St. Louis. Vol. 86, n.4, 161-164.

Svensson, L. 2000. "Open-Economy Inflation Targeting," Journal of International Economics 50, 155-183.

Svensson, L. 1999. Inflation targeting as a monetary policy rule. Journal of Monetary Economics 43, 607-654.

Svensson, L. L. 1997. Inflation targeting in an open economy: Strict or flexible inflation targeting. Mimeo.

Woodford, M. \& Giannoni, M.P. Optimal Inflation Targeting Rules. Mimeo

World Bank (2013) World Development Indicators http://databank.worldbank.org/ddp/home.do 